\title{
Alba-la-Romaine - étude préalable du théâtre antique
}

Audrey Saison

(2) OpenEdition

Journals

Édition électronique

URL : http://journals.openedition.org/adlfi/14545

ISSN : 2114-0502

Éditeur

Ministère de la culture

Référence électronique

Audrey Saison, "Alba-la-Romaine - étude préalable du théâtre antique », ADLFI. Archéologie de la France - Informations [En ligne], Rhône-Alpes, mis en ligne le 24 avril 2015, consulté le 21 avril 2019. URL : http://journals.openedition.org/adlfi/14545

Ce document a été généré automatiquement le 21 avril 2019

(c) Ministère de la Culture et de la Communication, CNRS 


\title{
Alba-la-Romaine - étude préalable du théâtre antique
}

\author{
Audrey Saison
}

\author{
Code INSEE de la commune : 07005 \\ Lien Atlas (MCC) : \\ http://atlas.patrimoines.culture.fr/atlas/trunk/index.php? \\ ap_theme=DOM_2.01.02\&ap_bbox=4.553;44.522;4.638;44.596
}

1 Dans le cadre du transfert de propriété du théâtre antique d'Alba-la-Romaine au Conseil général de l'Ardèche, un projet de valorisation et de restauration est mené sur l'édifice de spectacle, classé monument historique depuis 1959.

2 Une étude de diagnostic patrimonial est lancée en amont de la restauration. Celle-ci comporte, outre une analyse générale et sanitaire du bâtiment confiée à l'architecte Renzo Wieder (Architecture \& Héritage), une étude archéologique préalable conduite par la Cellule archéologique du Conseil général de l'Ardèche.

3 Cette étude revêt plusieurs aspects. En plus d'avoir nécessité une recherche sur l'histoire des découvertes archéologiques de l'édifice, elle a permis de vérifier par des sondages des points chronologiques et stratigraphiques.

4 Depuis sa découverte en 1819-1822, le théâtre a connu une vingtaine d'interventions qui ont rendu possible le dégagement total de la cavea à partir de 1982, des campagnes de restauration ont été lancées par la Conservation régionale des monuments historiques afin de stabiliser le monument. Sept rangées de gradins ont été reconstruites. À cette occasion, Pierre André, archéologue et architecte indépendant, a établi trois états dans la construction du théâtre. Depuis, plus aucune opération archéologique n'est venue alimenter ces propositions.

5 L'intervention archéologique a consisté à réaliser 4 sondages d'une superficie totale de $36,50 \mathrm{~m}^{2}$ : deux ont été implantés dans la cavea même et deux autres à l'extérieur, l'un au pied du mur d'enceinte, l'autre à la base du mur galerie. 
6 Le premier sondage a été ouvert sur une superficie de $22 \mathrm{~m}^{2}$, au sud du cinquième vomitoire (fig. 01). Une stratigraphie de 3,70 $\mathrm{m}$ a été observée. Le niveau le plus profond a atteint 186,90 m NGF. Il s'agit d'une couche d'argile grise montrant des traces d'oxydation orangée et de charbons de bois. Le recouvrement témoigne de l'apport d'importants remblais très organisés et répétés: blocs de basalte dans une matrice argileuse, puis mince couche de chaux uniforme. Une seconde étape se compose de nouveaux remblais plus massifs comptant 5 couches d'épaisseur et de natures fort variées. De gros blocs de basalte, sans matrice, sont alors apportés puis recouverts d'une succession de couches, notamment l'US 5 riche en céramiques et terre-cuites architecturales, provenant d'une démolition. Celle-ci a livré 797 tessons où dominent les céramiques communes claires $(44,9 \%)$, notamment des cruches et des mortiers à lèvre en bandeau. Les céramiques engobées rouges représentent $37,8 \%$ du total et offrent des plats, dont certains imitent les céramiques à vernis rouge pompéien, ainsi que des cruches à une anse et à panse carénée. Les céramiques fines sont également représentées par quelques tessons de céramique peinte et de vernis rouge pompéien, et par 14 tessons de sigillées italiques $(1,7 \%)$ dont certains appartiennent aux services II et III de Haltern. Les autres céramiques sont peu nombreuses : céramiques peintes, céramiques siliceuses décorées portant des traces graffitées longilignes, quelques-unes non tournées et enfin des amphores de Bétique et de Tarraconaise. Cet ensemble est daté de la période augustéenne. Ces remblais se terminent une nouvelle fois par une couche de chaux uniforme et homogène de 2 à $4 \mathrm{~cm}$ dont la fonction n'a pu être déterminée : niveau de stabilisation, d'assainissement ou de circulation? Deux murs rayonnants (MR 16 et 17) sont alors construits. L'un est posé sur la couche de chaux, l'autre la recoupe. Le reste de la stratigraphie montre des remblais contemporains de 1989.

7 Ce sondage révèle ainsi les aménagements de la cavea liés à la construction du premier théâtre : apport d'importants remblais pour combler la pente naturelle du site au sein d'un théâtre polygonal.

8 Le deuxième sondage se trouve dans la partie nord de la cavea, à l'angle du mur le plus ancien du théâtre, le mur polygonal (MP 15), et d'un mur rayonnant (MR 19), tous deux restaurés dans les années 1980. Le mur polygonal originel a été dégagé sur $1 \mathrm{~m}$ de haut. Il est construit sur 7 assises de blocs de calcaire équarris en opus vittatum. Ce mur possède un ressaut de fondation large de $30 \mathrm{~cm}$ à $187,27 \mathrm{~m}$ NGF, creusé dans l'argile naturelle orangée par une tranchée de fondation étroite. Les rares céramiques du comblement de cette tranchée livrent un terminus ante quem augustéen pour la construction du mur, confirmant son appartenance au premier état du théâtre. De gros blocs de basalte sont ensuite apportés. Enfin, un mur rayonnant (MR 19) est édifié sur ces remblais, recouvrant le mur polygonal.

Le troisième sondage a été implanté à l'extérieur sud du théâtre, au pied du mur galerie et du seuil d'accès au vomitoire. Il a révélé un aménagement antérieur à la construction du mur galerie. Il s'agit d'un petit fossé avec un empierrement dans une matrice argileuse grise dont les rares céramiques donnent une fourchette allant de la période augustéenne au milieu du $\mathrm{e}^{\mathrm{er}} \mathrm{s}$. apr. J.-C. Quelques remblais sont apportés avant que ne soit construit le mur galerie en tranchée étroite. La fondation de ce dernier est composée d'un hérisson de blocs de basalte puis de petits blocs de basalte qui sont noyés dans un mortier de chaux gris très couvrant. Seul un terminus post quem autour de 15/20 apr. J.-C. a pu être établi pour la construction de ce mur galerie. 
Le dernier sondage a été effectué au nord du théâtre, au pied du mur d'enceinte (ME 39). Celui-ci a pu être observé sur 4,10 m de hauteur, mais sa fondation n'a pu être atteinte (alti. inférieure à $184,95 \mathrm{~m}$.). Si le mur actuel a été entièrement remonté lors des restaurations des années 1984, celui qui se trouve sous le niveau de sol actuel est dans son état antique. La tranchée a mis au jour une quinzaine d'assises avec des joints tirés au fer. Une couche de remblai est ensuite apportée contre le mur d'enceinte ; elle livre un bol en sigillée de Gaule du Sud (Ritterling 8) daté entre 30/70 et 100 apr. J.-C., donnant ainsi un terminus ante quem pour le mur d'enceinte. Le mur galerie (MG 48) est ensuite construit parallèlement au mur d'enceinte. Retrouvé sur $1,46 \mathrm{~m}$ de longueur et $1 \mathrm{~m}$ de hauteur, il est chaîné à un mur de refend (M 40) long de $2 \mathrm{~m}$ qui s'appuie lui-même contre le mur d'enceinte.

11 Cette étude archéologique préalable ouvre à nouveau le dossier du théâtre antique, et souligne l'insuffisance des recherches depuis des décennies. La perspective de nouvelles explorations de ce monument-phare de la ville antique permettra sans nul doute de mieux le comprendre et de réactualiser ses données archéologiques.

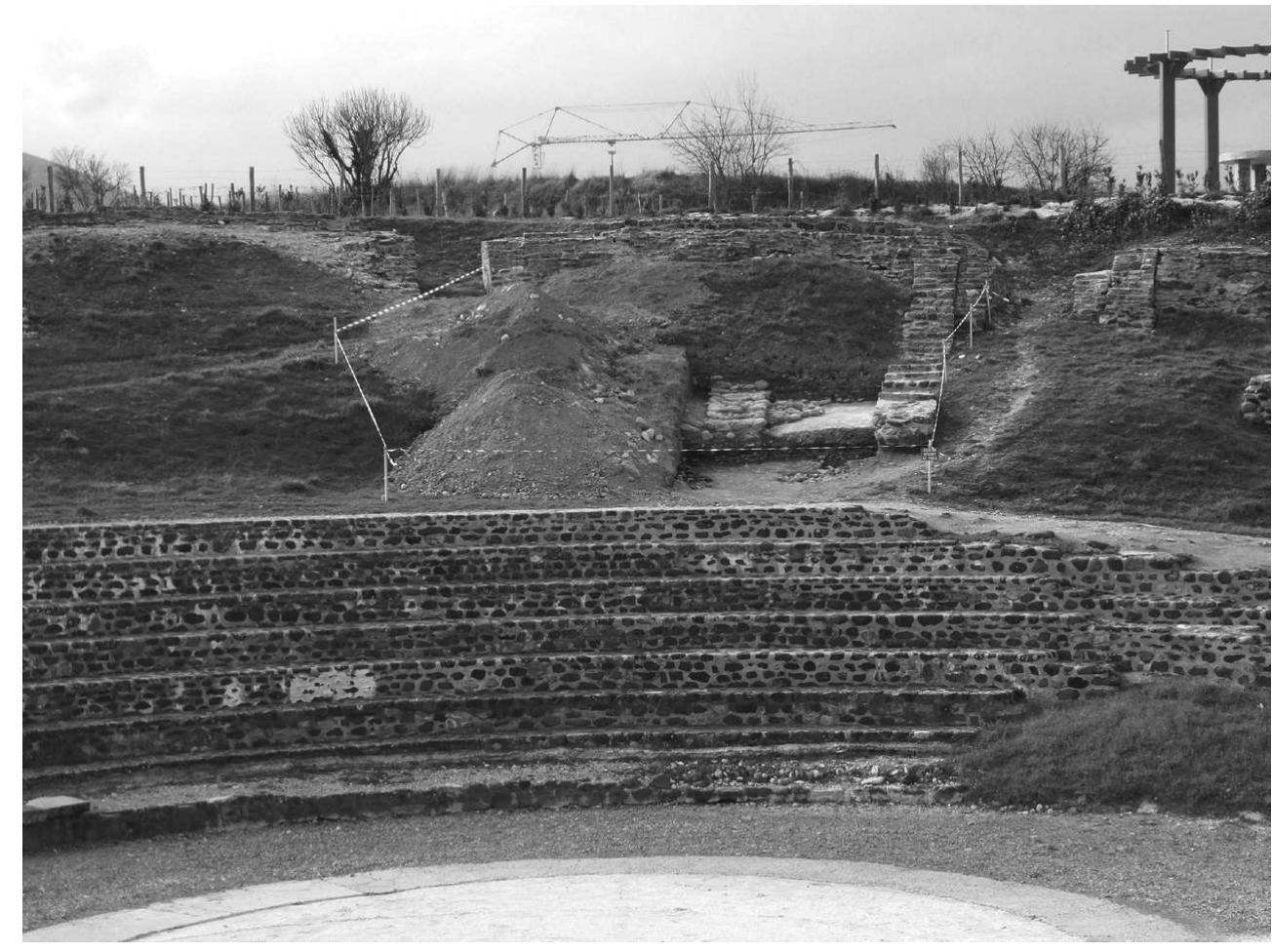

Fig. 01

Localisation du sondage 1 dans la cavea du théâtre d'Alba-la-Romaine Audrey Saison (Conseil général de l'Ardèche), 2013 
INDEX

Index chronologique : Antiquité, Haut-Empire

Index géographique : Rhône-Alpes, Ardèche (07), Alba-la-Romaine

peuple Helviens, Alba Helviorum

Keywords : public building, theatre, Early Empire, pottery

Mots-clés : édifice public, théâtre, céramique

operation Sondage (SD)

\section{AUTEURS}

AUDREY SAISON

Organisme de rattachement : Conseil Général de l'Ardèche 